\title{
Small-Signal Stability Analysis for Power System Frequency Regulation with Renewable Energy Participation
}

\author{
Tingyi He, ${ }^{1}$ Shengnan Li, ${ }^{1}$ Shuijun $\mathrm{Wu},{ }^{1}$ and $\mathrm{Ke} \mathrm{Li}\left(\mathbb{D}^{2,3}\right.$ \\ ${ }^{1}$ Yunnan Power Grid Co., Ltd., Electric Power Research Institute, Kunming 650200, China \\ ${ }^{2}$ Department of Electronic Engineering, Shantou University, Shantou 515041, China \\ ${ }^{3}$ Key Lab of Digital Signal and Image Processing of Guangdong Province, Shantou 515041, China \\ Correspondence should be addressed to Ke Li; ericlee@stu.edu.cn
}

Received 6 January 2021; Revised 20 January 2021; Accepted 22 March 2021; Published 5 April 2021

Academic Editor: Bo Yang

Copyright (C) 2021 Tingyi He et al. This is an open access article distributed under the Creative Commons Attribution License, which permits unrestricted use, distribution, and reproduction in any medium, provided the original work is properly cited.

With the improvement of the permeability of wind and photovoltaic (PV) energy, it has become one of the key problems to maintain the small-signal stability of the power system. Therefore, this paper analyzes the small-signal stability in a power system integrated with wind and solar energy. First, a mathematical model for small-signal stability analysis of power systems including the wind farm and PV station is established. And the characteristic roots of the New England power system integrated with wind energy and PV energy are obtained to study their small-signal stability. In addition, the validity of the theory is verified by the voltage drop of different nodes, which proves that power system integrated with wind-solar renewable energy participating in the frequency regulation can restore the system to the rated frequency in the shortest time and, at the same time, can enhance the robustness of each unit.

\section{Introduction}

Recently, with the exhaustion of fossil energy and the deterioration of the natural environment, renewable energy has attracted wide attention [1]. Wind energy and solar energy are the most widely used intermittent clean energy, and they are highly complementary in terms of resource and time distribution [2]. If wind and solar energy are integrated to form a wind-solar complementary energy system and participate in the frequency regulation of the power system, the utilization efficiency of intermittent energy can be improved to a certain extent and the global energy shortage can be alleviated $[3,4]$.

However, the random fluctuation of the output of wind and solar energy causes huge regulatory peak pressure to the power balance of the power system $[5,6]$; on the other hand, the power system is disturbed by small-signal all the time during operation $[7,8]$. An unstable system is difficult to operate properly in practice $[9,10]$. Thus, the analysis of small-signal stability of power system becomes one of the important tasks of power system [11, 12]. Literature [13] establishes a small-signal model of PV generation connected to a weak AC grid. The stability of PV power generation under different power grid strength and control parameters is studied by means of eigenvalue analysis. Literature [14] studies the influence of a large number of wind power generation on small-signal stability and corresponding control strategies to alleviate this negative influence. In [15], the Lyapunov stability criterion is used to analyze the stability research method of the integrated hybrid system. Stability research can be carried out for different renewable energy sources, such as the wind power generation system, photovoltaic system, and micro hydropower system. However, the above analysis regards wind-solar and other renewable energy sources as a perturbation of the power system and does not consider their participation in the frequency regulation of the power system. Therefore, it is not effective in analyzing the stability of the power system in which wind-solar renewable energy participate in the frequency regulation.

Thus, this paper studies the integrated energy system including wind power and PV system with the method of 
eigenvalue analysis and studies the oscillation modes of the power system when wind and solar power are connected separately, and when the wind farm is connected first and then the PV system is connected. The simulation model of the system is established and the New England power system is used to verify the correctness of the small-signal stability analysis.

The remaining of this paper is organized as follows: Section 2 develops the system modelling. In Section 3, smallsignal stability analysis is described. Comprehensive case studies are undertaken in Section 4. The different systems are discussed in Section 5 and Section 6 summarizes the main contributions of the paper.

\section{System Modelling}

2.1. Multimachine Power System Modelling. The third-order model of the $i$ th generator in a multimachine power system can be expressed by the following formula:

$$
\begin{aligned}
& \left\{\begin{array}{l}
\dot{\delta}_{i}=\omega_{i}-\omega_{0}, \\
\dot{\omega}_{i}=\frac{\omega_{0}}{2 H_{i}}\left[P_{m i}-\frac{D_{i}}{\omega_{0}}\left(\omega_{i}-\omega_{0}\right)-P_{e i}\right], \\
\dot{E}_{q i}^{\prime}=\frac{1}{T_{d 0 i}}\left(u_{f d i}+E_{f 0 i}-E_{q i}\right), \quad i=1,2, \ldots, n,
\end{array}\right. \\
& E_{q i}=E_{q i}^{\prime}-\left(x_{d i}-x_{d i}^{\prime}\right) I_{d i}, \\
& P_{e i}=\sum_{j=1}^{n} E_{q i}^{\prime} E_{q j}^{\prime} \beta_{i j}, \\
& Q_{e i}=\sum_{j=1}^{n} E_{q i}^{\prime} E_{q j}^{\prime} \alpha_{i j}, \\
& I_{d i}=\sum_{j=1}^{n} E_{q i}^{\prime} \alpha_{i j}, \\
& I_{q i}=\sum_{j=1}^{n} E_{q j}^{v} \beta_{i j}, \\
& V_{t i}=\sqrt{V_{d i}^{2}+V_{q i}^{2}}, \\
& V_{d i}=x_{q i} I_{q i} V_{d i}=E_{q j}^{\prime}-x_{d i}^{\prime} I_{d i} \\
& \alpha_{i j}=B_{i j} \cos \left(\delta_{i}-\delta_{j}\right)+G_{i j} \sin \left(\delta_{i}-\delta_{j}\right) \text {, } \\
& \beta_{i j}=B_{i j} \sin \left(\delta_{i}-\delta_{j}\right)+G_{i j} \cos \left(\delta_{i}-\delta_{j}\right),
\end{aligned}
$$

where subscript $i$ denotes the variables of the ith machine; $\delta_{i}$ is the relative rotor angle; $\omega_{i}$ is the generator rotor speed; $\omega_{0}$ is the system speed; $E_{q i}$ and $E_{q i}^{\prime}$ are the voltage and transient voltage on the $q$-axis; $P_{\mathrm{m} i}$ is the constant mechanical power input; $P_{\mathrm{e} i}$ is the electric power output; $V_{\mathrm{t} i}$ is the generator terminal voltage; $V_{d i}$ and $V_{q i}$ are the $d$-axis and $q$-axis generator terminal voltages; $x_{d i}$ and $x_{d i}^{\prime}$ are the $d$-axis synchronous and transient impedances; $x_{q i}$ is the $q$-axis synchronous impedance; $H_{i}$ is the rotor inertia; $T_{d 0 i}$ is the $\mathrm{d}$-axis transient short-circuit time constant; $I_{d i}$ and $I_{q i}$ are the $d$-axis and $q$-axis generator currents; $Y_{i j}$ is the equivalent admittance between the $i$ th and $j$ th nodes; $B_{i j}$ is the susceptance between $i$ and $j$ nodes; $G_{i j}$ is the conductance between $i$ and $j$ nodes; and $u_{\mathrm{f} d i}$ and $E_{\mathrm{f} d i}$ are the excitation voltage and the initial excitation voltage, respectively.

2.2. System Modelling of DFIG Based Wind Turbine. DFIG is connected to the power system through the voltage source converter, as shown in Figure 1 [16].

The aerodynamic mathematical model of the wind turbine can be described as [16]

$$
\begin{aligned}
P_{m} & =\frac{1}{2} \rho \pi R^{2} C_{p}(\lambda, \beta) v_{\text {wind }}^{3}, \\
\lambda & =\frac{\omega_{m} R}{v_{\text {wind }}}, \\
C_{p}(\lambda, \beta) & =c_{1}\left(\frac{c_{2}}{\lambda_{i}}-c_{3} \beta-c_{4}\right) e^{-\left(c_{5} / \lambda_{4}\right)}+c_{6} \lambda,
\end{aligned}
$$

with

$$
\frac{1}{\lambda_{i}}=\frac{1}{\lambda+0.08 \beta}-\frac{0.035}{\beta^{3}+1},
$$

where $\rho$ is the air density, $R$ denotes the radius of the wind turbine, and $v_{\text {wind }}$ means the wind speed. $C_{P}(\lambda, \beta)$ is a function of tip-speed-ratio $\lambda$ and blade pitch angle $\beta$ representing the power coefficient. A specific wind speed corresponds to a wind turbine rotational speed to obtain $C_{\text {Pmax }}$ namely, the maximum power coefficient and therefore tracks the maximum mechanical (wind) power. $\omega_{\mathrm{m}}$ denotes the wind turbine rotational speed [17].

The $4^{\text {th }}$-order mathematical model of DFIG can be described as

$$
\left\{\begin{array}{l}
\frac{\mathrm{d} i_{q s}}{\mathrm{~d} t}=\frac{\omega_{b}}{L_{s}^{\prime}}\left(-R_{1} i_{q s}+\omega_{s} L_{s}^{\prime} i_{q s}+\frac{\omega_{r}}{\omega_{s}} e_{q s}^{\prime}-\frac{1}{T_{r} \omega_{s}} e_{d s}^{\prime}-v_{q s}+\frac{L_{m}}{L_{r r}} v_{q r}\right) \\
\frac{\mathrm{d} i_{d s}}{\mathrm{~d} t}=\frac{\omega_{b}}{L_{s}^{\prime}}\left(-\omega_{s} L_{s}^{\prime} i_{q s}-R_{1} i_{q s}+\frac{1}{T_{r} \omega_{s}} e_{q s}^{\prime}+\frac{\omega_{r}}{\omega_{s}} e_{d s}^{\prime}-v_{d s}+\frac{L_{m}}{L_{r r}} v_{q r}\right) \\
\frac{\mathrm{d} e_{q s}^{v}}{\mathrm{~d} t}=\omega_{b} \omega_{s}\left[R_{2} i_{d s}-\frac{1}{T_{r} \omega_{s}} e_{q s}^{\prime}+\left(1-\frac{\omega_{r}}{\omega_{s}}\right) e_{d s}^{\prime}-\frac{L_{m}}{L_{r r}} v_{d r}\right] \\
\frac{\mathrm{d} e_{d s}^{\prime}}{\mathrm{d} t}=\omega_{b} \omega_{s}\left[-R_{2} i_{q s}-\left(1-\frac{\omega_{r}}{\omega_{s}}\right) e_{q s}^{\prime}-\frac{1}{T_{r} \omega_{s}} e_{d s}^{\prime}+\frac{L_{m}}{L_{r r}} v_{q r}\right]
\end{array}\right.
$$

where $\omega_{b}$ represents the electrical base speed, $\omega_{s}$ denotes the synchronous angle speed, and $\omega_{\mathrm{r}}$ means the rotor angle speed; $e_{d s}^{\prime}$ and $e_{q s}^{\prime}$ denote the equivalent $d$-axis and $q$-axis 


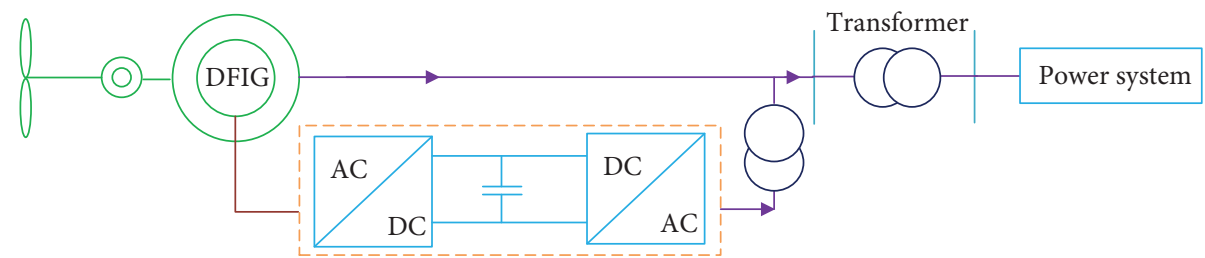

FIGURE 1: The grid-connected structure of wind turbine.

( $d q^{-}$) internal voltages; $i_{d s}$ and $i_{q s}$ are the $d q$-stator currents; $v_{d s}$ and $v_{q s}$ represent the $d q$-stator terminal voltages; and $v_{d r}$ and $v_{q r}$ are the $d q$-rotor voltages. $L_{\mathrm{m}}$ means mutual inductance.

The pitch angle control system is designed to improve wind energy conversion efficiency and make wind turbine output stable. Its model can be described as follows:

$$
\frac{\mathrm{d} \beta}{\mathrm{d} t}=\frac{1}{T_{\beta}}\left(\beta_{\text {ref }}-\beta\right),
$$

where $\beta_{\text {ref }}$ is the reference value of pitch angle; $T_{\beta}$ is the inertia time constant of the pitch control system.

The grid-side converter which is directly connected with the power system has the main function of maintaining constant capacitive voltage under the control of the DC regulating system and the function of adjusting the power factor. The DC sides of both converters are supported by a common capacitor. The power equation of the converter can be described as [18]

$$
\left\{\begin{array}{l}
P_{r}=P_{g}+P_{D C}, \\
P_{r}=v_{d r} i_{d r}+v_{q r} i_{q r}, \\
P_{g}=v_{d g} i_{d g}+v_{q g} i_{q g}, \\
P_{\mathrm{DC}}=v_{\mathrm{DC}} i_{\mathrm{DC}}=-C v_{\mathrm{DC}} \frac{\mathrm{d} v_{\mathrm{DC}}}{\mathrm{d} t},
\end{array}\right.
$$

where $P_{r}$ is the active power of the AC terminal of the machine side converter and $P_{g}$ is the active power of the AC terminal of the grid-side converter. $P_{\mathrm{DC}}$ is the active power of the capacitor tie line; $i_{d r}$ and $i_{q r}$ are the $d-q$ axis components of rotor current respectively; $i_{d g}$ and $i_{q g}$ are the $\mathrm{d}-\mathrm{q}$ axis components of the system side converter current, respectively; $v_{d g}$ and $v_{q g}$ are the $d-q$ axis components of the system side converter voltage respectively; $v_{\mathrm{DC}}$ and $i_{\mathrm{DC}}$ are the current and voltage of the DC link in the converter; $C$ is the capacity of the capacitor.

Equation (6) can be rewritten as

$$
C v_{\mathrm{DC}} \frac{\mathrm{d} v_{\mathrm{DC}}}{\mathrm{d} t}=v_{d g} i_{d g}+v_{q g} i_{q g}-\left(v_{d r} i_{d r}+v_{q r} i_{q r}\right) .
$$

2.3. Modelling of PV System. The control structure of the PV system is shown in Figure 2 [19].

According to Kirchhoff's law, the $U-I$ equation of PV cell can be described as

$$
\begin{aligned}
I & =I_{\mathrm{sc}}^{\prime}\left\{1-C_{1}\left[e^{\left(U /\left(C_{2} U_{\mathrm{oc}}\right)\right)}-1\right]\right\}, \\
C_{1} & =\left(1-\frac{I_{m}^{\prime}}{I_{\mathrm{sc}}^{\prime}}\right) e^{\left(-U_{m}^{\prime}\left(C_{2} U_{\mathrm{oc}}\right)\right)}, \\
C_{2} & =\left(\frac{U_{m}^{\prime}}{U_{\mathrm{oc}}^{\prime}}-1\right)\left[\ln \left(1-\frac{I_{m}^{\prime}}{I_{\mathrm{sc}}^{\prime}}\right)\right]^{-1}, \\
I_{\mathrm{sc}}^{\prime} & =I_{\mathrm{sc}} \Delta I, \\
I_{m}^{\prime} & =I_{m} \Delta I, \\
U_{\mathrm{oc}}^{\prime} & =U_{\mathrm{oc}} \Delta U, \\
U_{m}^{\prime} & =U_{m} \Delta U, \\
\Delta I & =\frac{\left[1+\alpha\left(T-T_{\mathrm{ref}}\right)\right] S}{S_{\mathrm{ref}}}, \\
\Delta U & =\left[1-\gamma\left(T-T_{\mathrm{ref}}\right)\right] \ln \left[e+\beta\left(S-S_{\mathrm{ref}}\right)\right],
\end{aligned}
$$

where $I_{\mathrm{sc}}$ is the short-circuit current; $U_{\mathrm{oc}}$ is the open-circuit voltage; $U_{m}$ is the voltage at maximum power; $I_{m}$ is the current at maximum power; $S_{\text {ref }}$ is the illumination intensity under standard environment, which is $1 \mathrm{~kW} / \mathrm{m}^{2} . T_{\text {ref }}$ is the temperature in the standard environment, which is $25^{\circ} \mathrm{C} . I_{\mathrm{sc}}^{\prime}$, $U_{\mathrm{oc}}{ }^{\prime}, I_{m}^{\prime}$, and $U_{m}^{\prime}$ are, respectively, the correction values of $I_{\mathrm{sc}}$ and $U_{m}$ under different environments. $\alpha$ and $\gamma$ are temperature compensation coefficients; and $\beta$ is the compensation coefficient of PV irradiation.

In addition, DC/DC converter mainly plays the role of Boost and power transformation, it can be described as

$$
\left\{\begin{array}{l}
P_{\mathrm{pv} 2}=f_{1}\left(P_{\mathrm{pv} 1}\right)=P_{\mathrm{pv} 1}, \\
V_{\mathrm{pv} 1}=f_{2}\left(V_{D}, V_{p v m 1}\right)=V_{D} .
\end{array}\right.
$$

DC link is the intermediate link connecting DC side and AC side, namely, the DC bus capacitance model. According to the capacitance energy and voltage relationship, the DC link model can be described as

$$
\left\{\begin{array}{l}
\frac{\mathrm{d} E_{C}}{\mathrm{~d} t}=P_{\mathrm{PV} 2}-P_{D e} \\
E_{C}=\frac{1}{2 C V_{D}^{2}} .
\end{array}\right.
$$




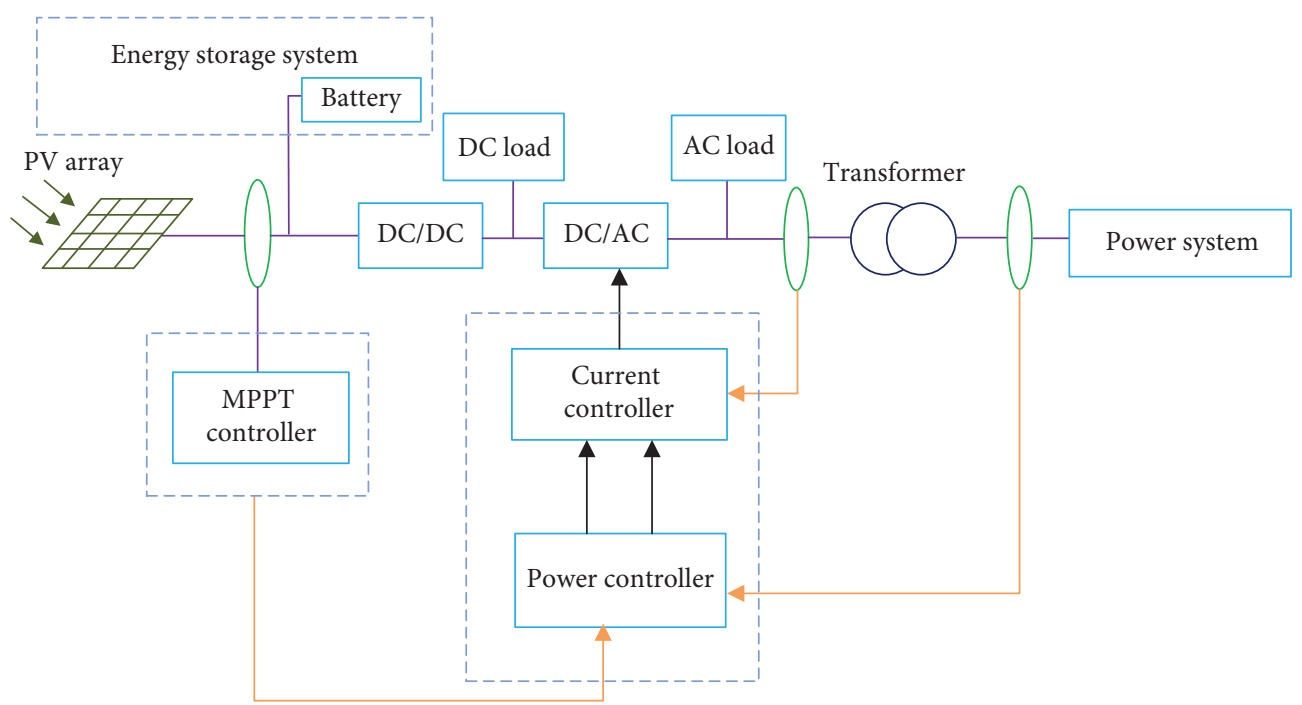

Figure 2: The control structure block diagram of the PV system.

where $P_{\mathrm{PV} 2}$ is the DC side input power of the DC link; $P_{p v e}$ is the output power of the DC link inverter side; $C$ is the capacitance value of the DC link capacitance; $V_{D}$ is the voltage value of the dc link; the $E_{C}$ is the amount of energy stored on a capacitor.

The wind-solar complementary energy system has three operating states: first, the wind turbine generated independently; second, the PV array independent power generation state; and third, wind-solar complementary power generation. Wind speed, solar radiation, load power consumption, and charging and discharging capacity of the energy storage device all determine the operation state of the wind-solar complementary energy system. Due to the randomness of these factors, the stability of the power system is bound to be affected to some extent. Therefore, it is necessary to analyze the stability of the small-signal of the power system integrated with renewable energy. The control structure diagram of the wind-solar energy system is giving in Figure 3.

\section{Small-Signal Stability Analysis}

The Lyapunov linearization method is related to the local stability of nonlinear systems. The basic idea is to obtain the local stability of nonlinear systems near their equilibrium operation points from the linear approximation stability property of nonlinear systems [20-22].

For the dynamic characteristic differential-algebraic equation of the power system, linearization at the steadystate operating point $\left(x_{0}, y_{0}\right)$ can be obtained as follows [23-25]:

$$
\left[\begin{array}{c}
\frac{\mathrm{d} \Delta x}{\mathrm{~d} t} \\
0
\end{array}\right]=\left[\begin{array}{cc}
\widetilde{A} & \widetilde{B} \\
\widetilde{C} & \widetilde{D}
\end{array}\right]\left[\begin{array}{c}
\Delta x \\
\Delta y
\end{array}\right],
$$

where $\Delta x$ represents the state variable that describes the dynamic characteristics of the power system in the system of differential equations and $\Delta y$ represents the operating parameters of the system in algebraic equations. $\widetilde{A}, \widetilde{B}, \widetilde{C}, \widetilde{D}$ are, respectively, their partial derivatives at steady-state operating point $\left(x_{0}, y_{0}\right)$.

Omitting operation parameter $y$, the following equation can be obtained:

$$
\frac{\mathrm{d} \Delta x}{\mathrm{~d} t}=A \Delta x
$$

with

$$
\begin{aligned}
A & =\widetilde{A}-\widetilde{B} \widetilde{D}^{-1} \widetilde{C}, \\
\widetilde{A} & =\left[\begin{array}{cccc}
A_{1} & 0 & 0 & 0 \\
0 & A_{2} & 0 & 0 \\
0 & 0 & A_{3} & 0 \\
0 & 0 & 0 & A_{10}
\end{array}\right], \\
\widetilde{B} & =\left[\begin{array}{ccccc}
B_{1} & 0 & 0 & 0 & 0 \\
0 & B_{2} & 0 & 0 & 0 \\
0 & 0 & B_{3} & 0 & 0 \\
0 & 0 & 0 & B_{10} & 0
\end{array}\right], \\
\widetilde{C} & =\left[\begin{array}{cccc}
-C_{1} & 0 & 0 & 0 \\
0 & -C_{2} & 0 & 0 \\
0 & 0 & -C_{3} & 0 \\
0 & 0 & 0 & -C_{10} \\
0 & 0 & 0 & 0
\end{array}\right], \\
\widetilde{D} & =\left[\begin{array}{ccc}
Y_{G G}-D_{G} & Y_{G L} \\
Y_{L G} & Y_{L L}
\end{array}\right] .
\end{aligned}
$$

Matrix A is usually called the state matrix of the system. The stability of the analyzed system at the steady-state operating point $(x, y)$ can be judged by obtaining the eigenvalue of matrix $A$ [26-28]: 


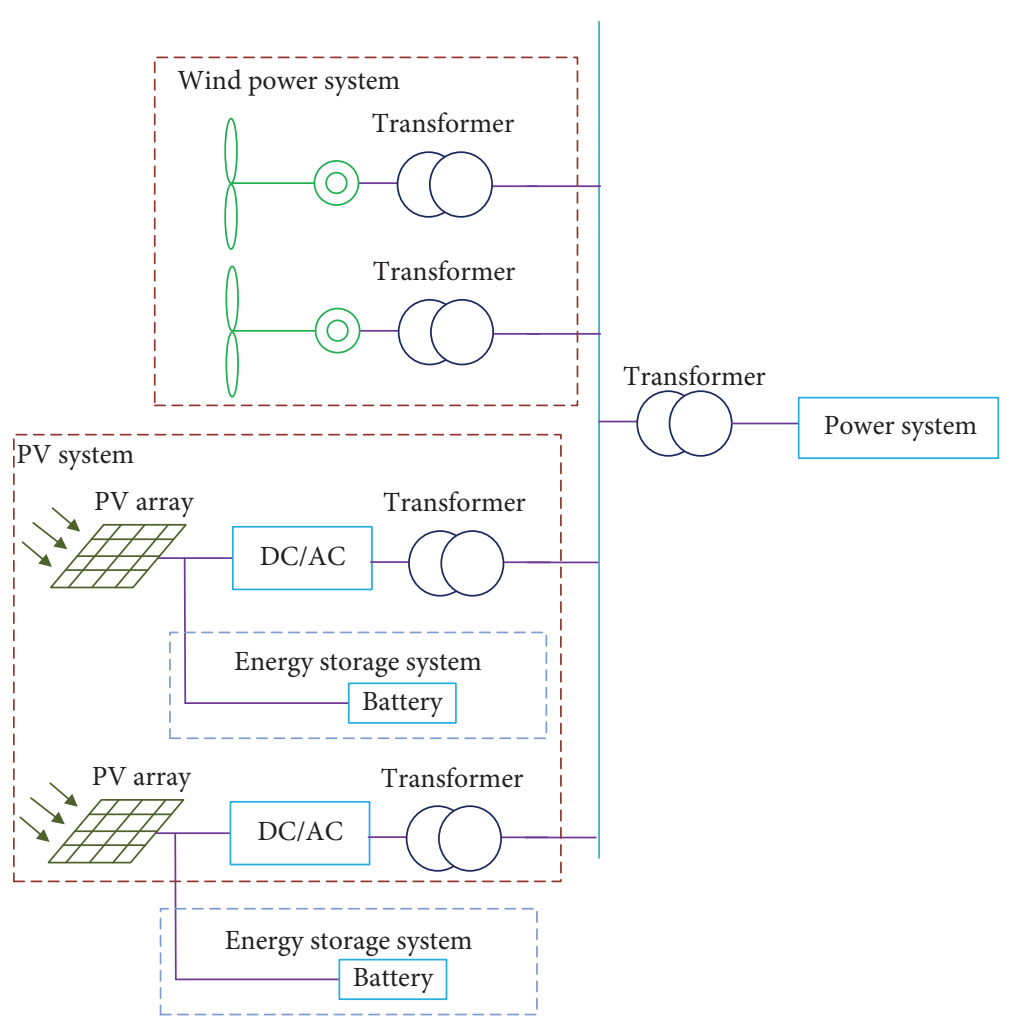

FIGURE 3: Control structure diagram of the wind-solar energy system.

(a) When the real part of all eigenvalues of $A$ is negative, it means that the actual power system can maintain stability when the equilibrium point encounters a small-signal.

(b) When at least one real part of all eigenvalues of $A$ is positive, it means that the actual power system will lose stability when it encounters a small-signal at the equilibrium point.

(c) When all eigenvalues of $A$ have no positive eigenvalue of the real part, but at least one eigenvalue of the real part is zero, then the linearized system is in $A$ critical stable state, but it cannot be used to judge whether the actual power system is stable at the equilibrium point.

(d) A real characteristic root corresponds to a nonoscillating mode. The modes represented by negative real characteristic roots are attenuated, and the greater the absolute value, the faster the corresponding modes decay.

(e) Complex characteristic roots always appear as conjugate pairs and can be described as

$$
\lambda=\sigma \pm j \omega
$$

Complex eigenvalues are always composed of conjugate pairs, which can be described as the negative real part represents the damping oscillation mode [29-31]. The positive real part represents the increased oscillation, and the real part of the eigenvalue represents the damping of the system oscillation, while the imaginary part represents the frequency of the system oscillation [32]. The frequency of oscillation can be expressed as [33]

$$
f=\frac{\omega}{2 \pi} \text {. }
$$

The damping ratio is defined as

$$
\zeta=\frac{-\sigma}{\sqrt{\sigma^{2}+\omega^{2}}}
$$

It represents the attenuation characteristic of the oscillation amplitude.

\section{Case Studies}

The proposed methodology is tested on the New England power system, as shown in Figure 4. It consists of 39 buses and 10 generators, and the New York grid connected to the New England power system is represented by the first generator. In addition, detailed system parameters are shown in literature [16]. The proposed methodology has been developed in MATLAB 2017 b environment. In order to analyze the damping characteristics of interconnected systems when wind farm and PV system are connected to the power system, the eigenvalue analysis is carried out for the following four working conditions:

(a) Initial system

(b) Only wind farms are connected on bus \#1 and output $5 \mathrm{MW}$ 


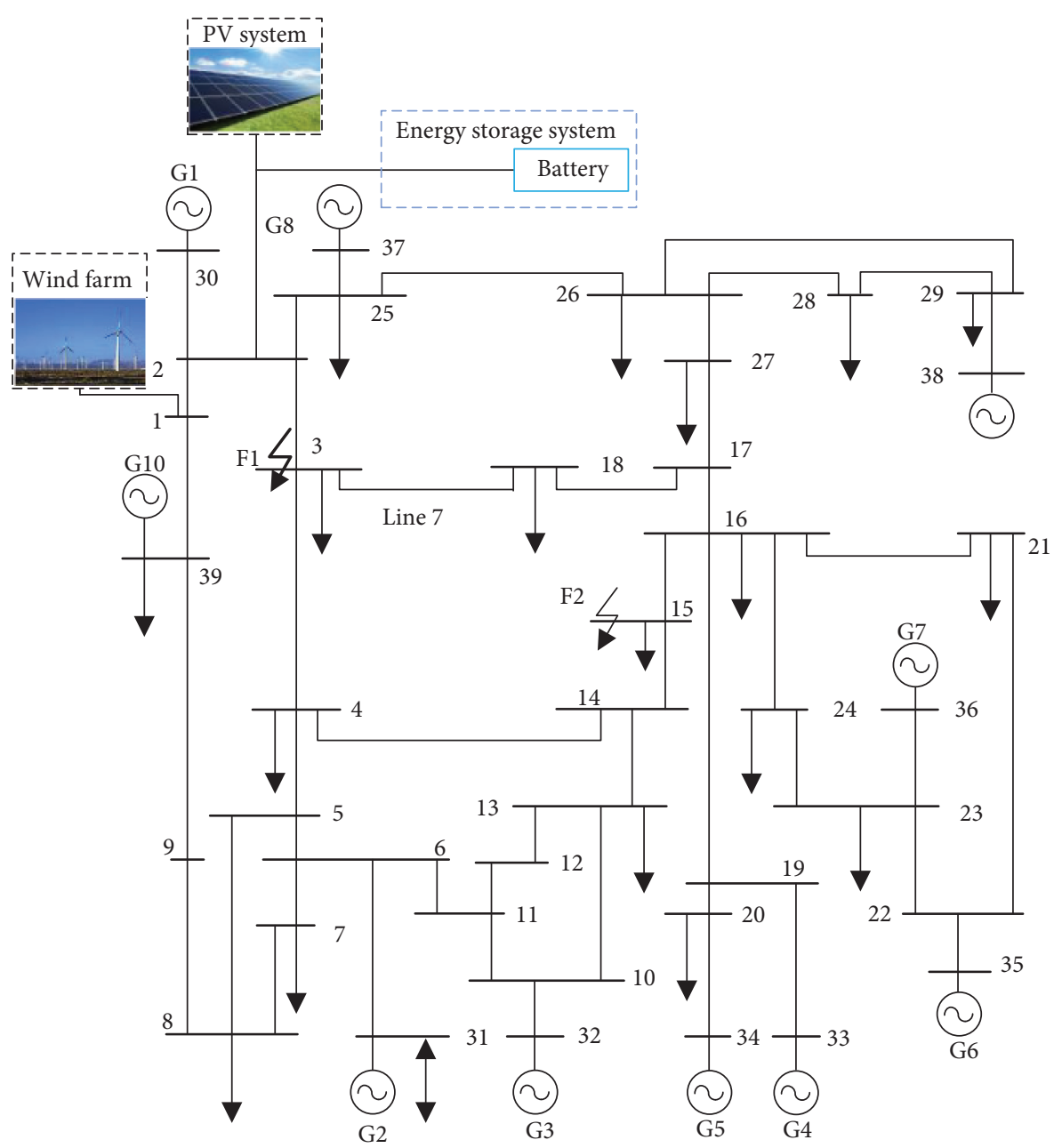

Figure 4: The configuration of the New England power system.

TABLE 1: Eigenvalues of the system.

\begin{tabular}{|c|c|c|c|c|}
\hline Case & Characteristic root & Fluctuating frequency $(\mathrm{Hz})$ & Damping ratio & Relevant units \\
\hline \multirow{9}{*}{ Without wind or PV } & $-0.9789 \pm j 6.8784$ & 1.0947 & 0.1408 & $\mathrm{G} 1, \mathrm{G} 2$ \\
\hline & $-1.2415 \pm \mathrm{j} 7.4895$ & 1.2332 & 0.1582 & G1, G3 \\
\hline & $-0.3021 \pm \mathrm{j} 4.1298$ & 0.6573 & 0.0730 & G1, G5 \\
\hline & $-0.8243 \pm j 7.1776$ & 1.0065 & 0.1292 & G1, G8 \\
\hline & $-0.5194 \pm \mathrm{j} 7.9844$ & 0.9476 & 0.0869 & G1, G9 \\
\hline & $-0.4123 \pm \mathrm{j} 4.4777$ & 0.7937 & 0.0824 & G1, G10 \\
\hline & $-0.6512 \pm j 6.6744$ & 0.8156 & 0.1260 & G2, G3 \\
\hline & $-1.1654 \pm \mathrm{j} 6.2732$ & 0.7402 & 0.2430 & $\mathrm{G} 2, \mathrm{G} 4$ \\
\hline & $-0.9426 \pm \mathrm{j} 5.0038$ & 1.1116 & 0.1337 & G2, G5 \\
\hline \multirow{10}{*}{ Only wind } & $-1.1584 \pm j 7.1777$ & 1.1423 & 0.1593 & G1, G2 \\
\hline & $-1.3828 \pm j 7.9844$ & 1.2707 & 0.1706 & G1, G3 \\
\hline & $-0.5108 \pm \mathrm{j} 4.4778$ & 0.7126 & 0.1133 & G1, G5 \\
\hline & $-1.0342 \pm j 6.6744$ & 1.0622 & 0.1531 & G1, G8 \\
\hline & $-0.7109 \pm j 6.2732$ & 0.9984 & 0.1126 & G1, G9 \\
\hline & $-0.4223 \pm j 5.0038$ & 0.7963 & 0.0841 & G1, G10 \\
\hline & $-0.6718 \pm j 5.1594$ & 0.8211 & 0.1291 & G2, G3 \\
\hline & $-1.2612 \pm j 4.8112$ & 0.7657 & 0.2535 & $\mathrm{G} 2, \mathrm{G} 4$ \\
\hline & $-1.1018 \pm \mathrm{j} 7.2496$ & 1.1538 & 0.1502 & G2, G5 \\
\hline & $-0.4291 \pm \mathrm{j} 0.7962$ & 0.1267 & 0.4744 & G1-G10, DFIG \\
\hline
\end{tabular}


TABLE 1: Continued.

\begin{tabular}{|c|c|c|c|c|}
\hline Case & Characteristic root & Fluctuating frequency $(\mathrm{Hz})$ & Damping ratio & Relevant units \\
\hline Only PV & $\begin{array}{l}-1.3548 \pm \mathrm{j} 7.5049 \\
-1.5051 \pm \mathrm{j} 8.1882 \\
-0.7568 \pm \mathrm{j} 4.8878 \\
-1.2497 \pm \mathrm{j} 7.0336 \\
-1.0015 \pm \mathrm{j} 6.7575 \\
-0.5817 \pm \mathrm{j} 5.2695 \\
-0.7693 \pm \mathrm{j} 5.3220 \\
-1.2929 \pm \mathrm{j} 4.8640 \\
-1.2851 \pm \mathrm{j} 7.5551 \\
-0.6627 \pm \mathrm{j} 1.1856\end{array}$ & $\begin{array}{l}1.1944 \\
1.3031 \\
0.7779 \\
1.1194 \\
1.0755 \\
0.8386 \\
0.8470 \\
0.7741 \\
1.2024 \\
0.1886\end{array}$ & $\begin{array}{l}0.1776 \\
0.1807 \\
0.1530 \\
0.1749 \\
0.1466 \\
0.1097 \\
0.1431 \\
0.2569 \\
0.1677 \\
0.4879\end{array}$ & $\begin{array}{c}\text { G1, G2 } \\
\text { G1, G3 } \\
\text { G1, G5 } \\
\text { G1, G8 } \\
\text { G1, G9 } \\
\text { G1, G10 } \\
\text { G2, G3 } \\
\text { G2, G4 } \\
\text { G2, G5 } \\
\text { G1-G10, PV }\end{array}$ \\
\hline Combination of wind and PV & $\begin{array}{l}-1.4818 \pm j 7.7166 \\
-1.5323 \pm j 8.2336 \\
-0.8368 \pm j 5.0210 \\
-1.2958 \pm j 7.1105 \\
-1.0858 \pm j 6.8981 \\
-0.7138 \pm j 5.4895 \\
-0.9275 \pm j 5.5855 \\
-1.4302 \pm j 5.0927 \\
-1.5478 \pm j 7.9928 \\
-0.8182 \pm j 1.4446 \\
-0.7283 \pm j 5.0665\end{array}$ & $\begin{array}{l}1.2281 \\
1.3104 \\
0.7991 \\
1.1316 \\
1.0978 \\
0.8736 \\
0.8889 \\
0.8105 \\
1.2721 \\
0.2299 \\
0.8064\end{array}$ & $\begin{array}{l}0.1885 \\
0.1829 \\
0.1643 \\
0.1792 \\
0.1554 \\
0.1289 \\
0.1638 \\
0.2703 \\
0.1901 \\
0.4928 \\
0.1423\end{array}$ & $\begin{array}{c}\text { G1, G2 } \\
\text { G1, G3 } \\
\text { G1, G5 } \\
\text { G1, G8 } \\
\text { G1, G9 } \\
\text { G1, G10 } \\
\text { G2, G3 } \\
\text { G2, G4 } \\
\text { G2, G5 } \\
\text { G1-G10, DFIG } \\
\text { G1-G10, PV }\end{array}$ \\
\hline
\end{tabular}

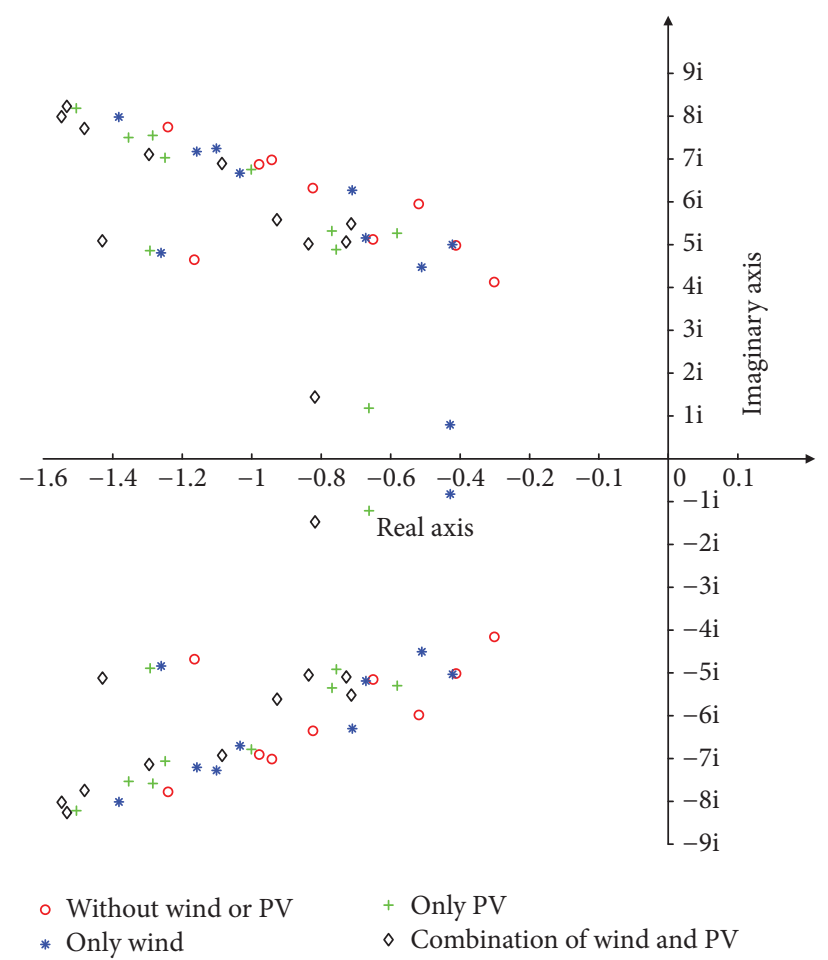

FIGURE 5: Root loci distribution of different conditions.

(c) Only the PV system is connected on bus \#2 and output $5 \mathrm{MW}$

(d) Wind farms and the PV system are both connected on bus \#1 and bus \#2, respectively, and the output is $2.5 \mathrm{MW}$ and $2.5 \mathrm{MW}$, respectively

Table 1 shows the partial eigenvalues of the system in four cases. It can be seen that when wind farm and PV system are connected separately, their characteristic roots are all far away from the imaginary axis. In particular, after the addition of wind and solar energy, the characteristic root distribution was well improved, which indicates that wind power and PV system independent access system both can significantly improve the stability and, at the same time, are complementary to each other. And Root loci distribution of different conditions is given in Figure 5. 

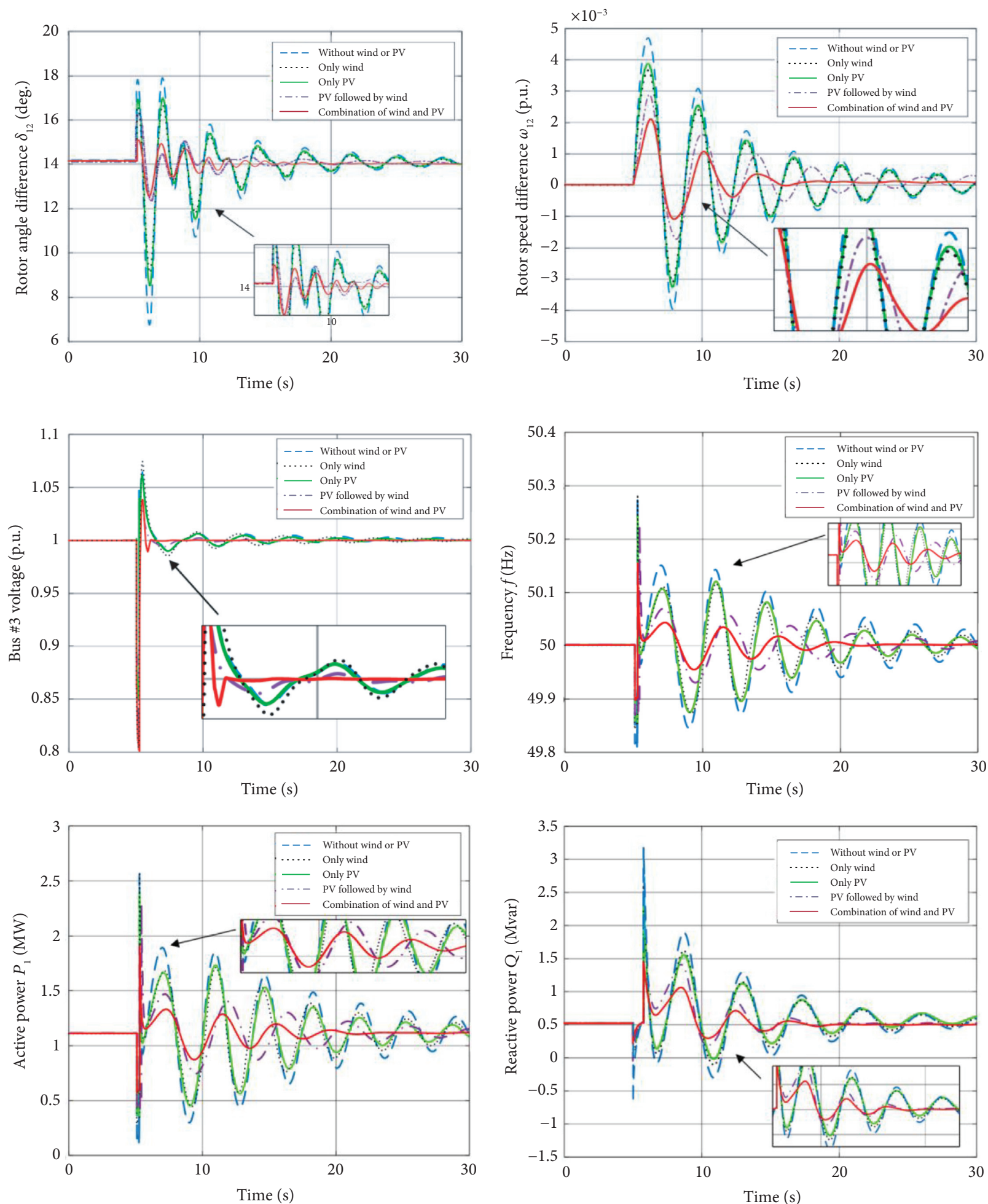

Figure 6: System responses obtained under bus \#3 voltage drop.

4.1. Bus \#3 Voltage Drop. In order to further verify the validity of the characteristic roots above, voltage drop 0.8 p.u. occurred at bus \#3 when $t=5 \mathrm{~s}$ and recovered after $0.1 \mathrm{~s}$. The corresponding system response is shown in Figure 6. It can be seen that the system that does not involve wind-solar renewable energy in frequency modulation has the worst recovery ability after small-signal, while, with the connection of wind and solar energy, the recovery ability of the system after small-signal is improved. In particular, the system combination of wind and solar energy has the best recovery from small-signal and the ability to adjust the system frequency to near the rated frequency in the shortest amount of time. 

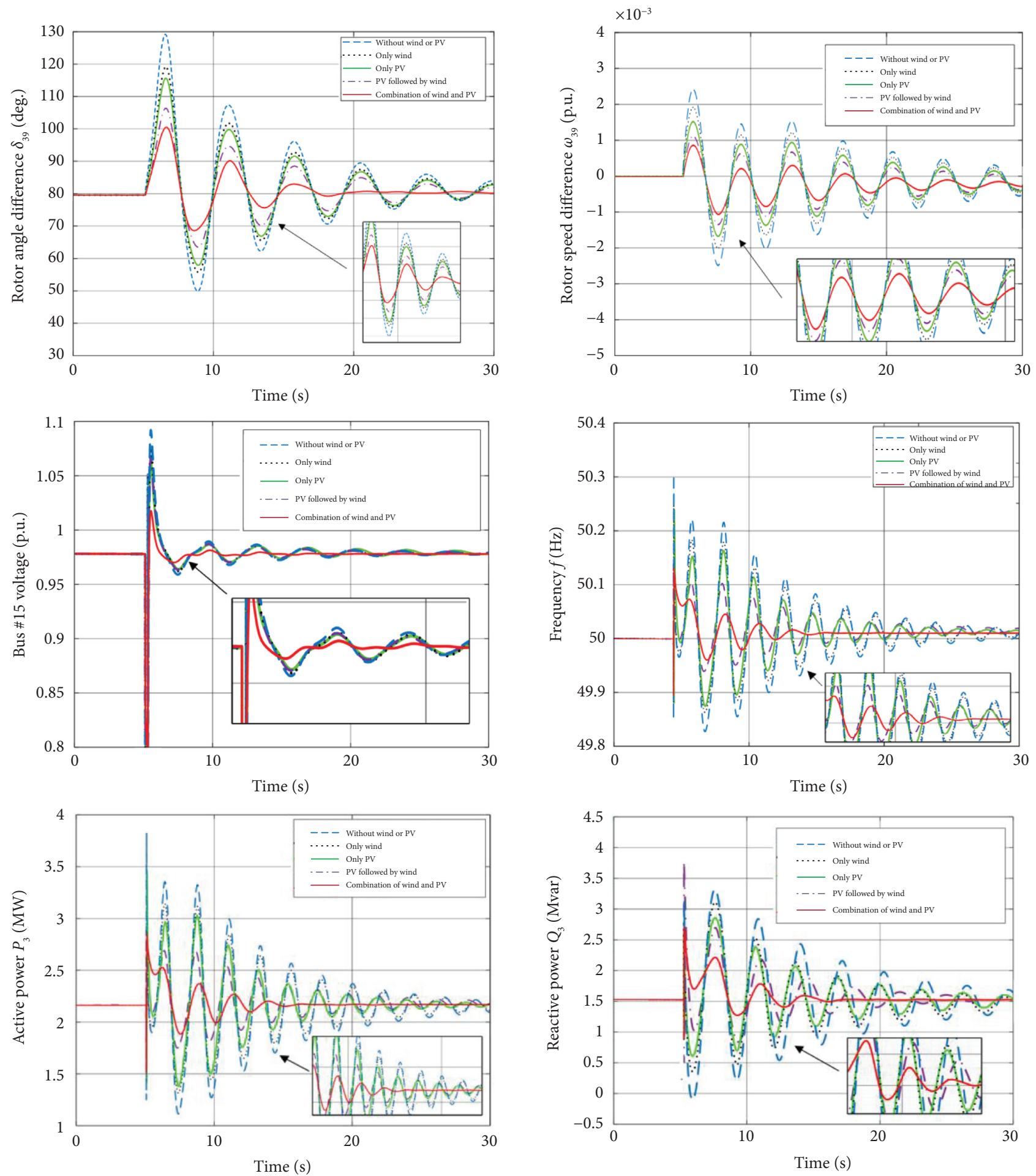

FIgURE 7: System responses obtained under bus \#15 voltage drop.

4.2. Bus \#15 Voltage Drop. In order to verify the recovery ability of the system after receiving small-signal at different positions, voltage drop 0.8 p.u. occurred at bus \#15 when $t=5 \mathrm{~s}$ and recovered after $0.1 \mathrm{~s}$. And the voltage was restored after $0.1 \mathrm{~s}$. The corresponding system response is shown in Figure 7. It can be found that, with the system combination of wind and PV, the rotor angle difference regulation capacity of generator $G_{1}$ is significantly improved, its oscillation amplitude is significantly reduced, and it is restored to the rated value in the shortest time. In addition, it has the best regulation ability for active power and reactive power and will adjust the system to the steady-state in the shortest period, so that the system subject to small-signal has the strongest frequency regulation ability. 

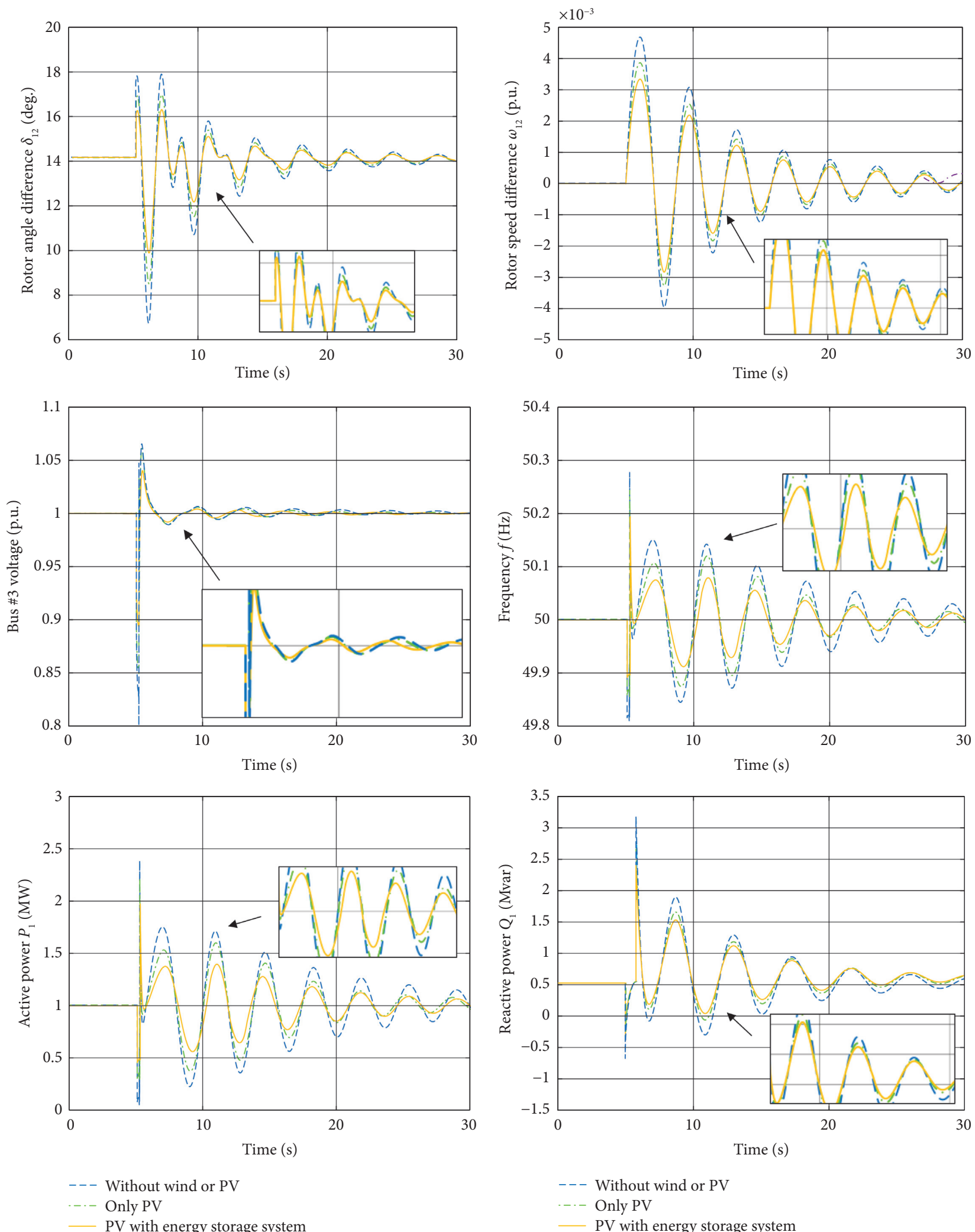

Figure 8: System responses obtained under bus \#3 voltage drop.

\section{Discussion}

5.1. Bus \#3 Voltage Drop. In order to further study the positive effect of the energy storage system on the PV station, based on the above case, this paper considers that the energy storage system is configured in the PV station connected to bus \#2. In addition, voltage drop 0.8 p.u. occurred at bus \#3 when $5 \mathrm{~s}$ and recovered after $0.1 \mathrm{~s}$, and its system response is 

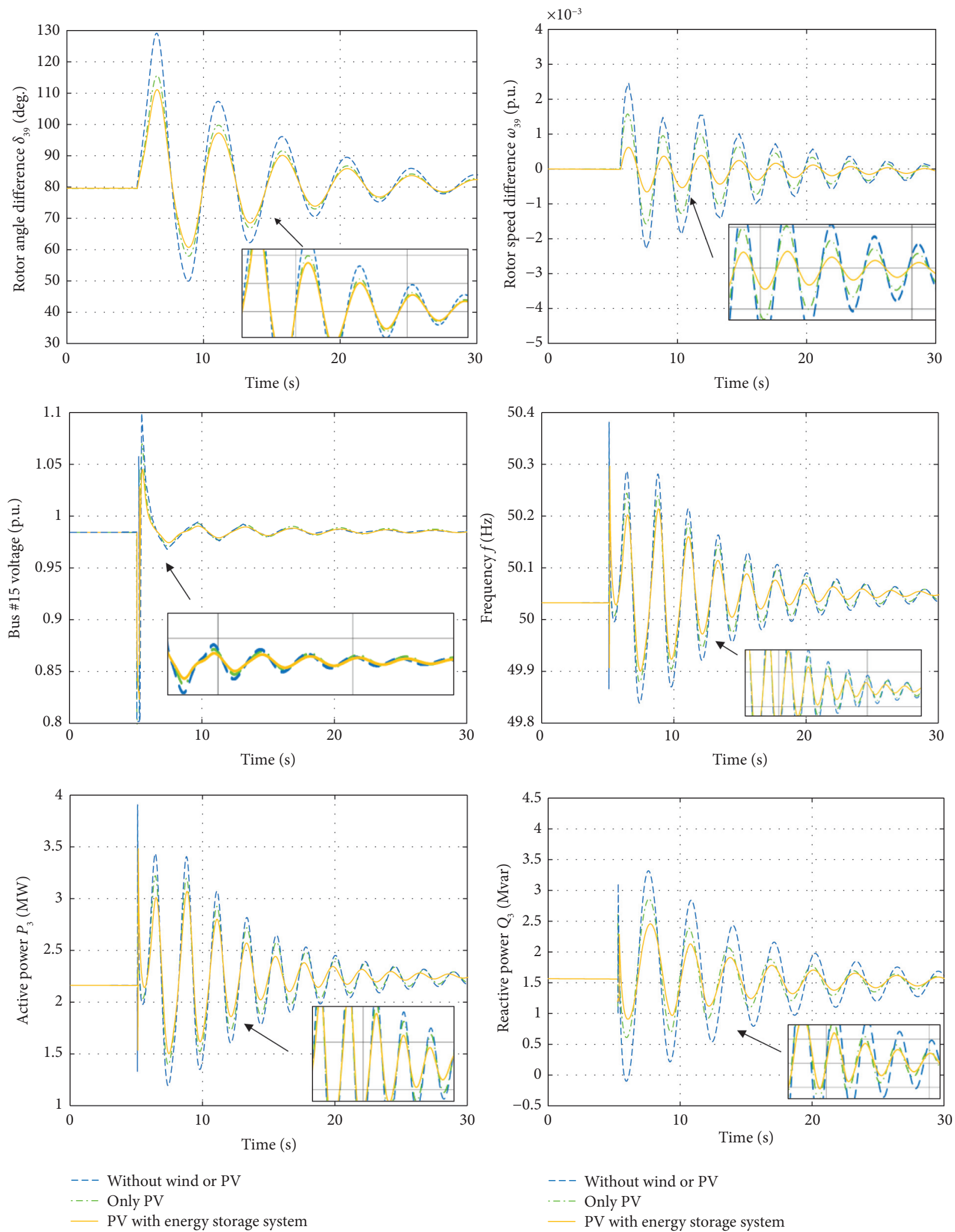

FIGURE 9: System responses obtained under bus \#15 voltage drop.

shown in Figure 8. It can be seen that after the PV system is configured with the energy storage system, the stability of small-signal is better. Compared with the initial PV system, it can restore system frequency in a relatively short time.
5.2. Bus \#15 Voltage Drop. Consider the following fault: voltage drop 0.8 p.u. occurred at bus \#15 with $5 \mathrm{~s}$ and recovered after $0.1 \mathrm{~s}$. To verify the stability of the system in case of failure at different locations, its system response is shown 
TABLE 2: IAE indices of six parameters acquired in two fault locations (in p.u.).

\begin{tabular}{|c|c|c|c|c|c|c|}
\hline Cases: bus \#3 voltage drop & $\mathrm{IAE}_{\delta 12}$ & $\mathrm{IAE}_{\omega 12}$ & $\mathrm{IAE}_{U 3}$ & $\mathrm{IAE}_{f}$ & $\mathrm{IAE}_{P 1}$ & $\mathrm{IAE}_{\mathrm{Q} 1}$ \\
\hline Without wind or PV & 1.155 & $1.239 \times 10^{-2}$ & 0.785 & 0.094 & 0.545 & 0.759 \\
\hline Only wind & 0.956 & $1.058 \times 10^{-2}$ & 0.696 & 0.089 & 0.516 & 0.694 \\
\hline Only PV & 0.911 & $1.042 \times 10^{-2}$ & 0.677 & 0.087 & 0.505 & 0.696 \\
\hline PV with energy storage system & 0.870 & $1.024 \times 10^{-2}$ & 0.651 & 0.083 & 0.489 & 0.675 \\
\hline PV followed by wind & 0.810 & $0.985 \times 10^{-2}$ & 0.594 & 0.081 & 0.470 & 0.648 \\
\hline Combination of wind and PV & 0.715 & $0.898 \times 10^{-2}$ & 0.452 & 0.076 & 0.441 & 0.617 \\
\hline Cases: bus \#15 voltage drop & $\mathrm{IAE}_{\delta 39}$ & $\mathrm{IAE}_{\omega 39}$ & $\mathrm{IAE}_{U 15}$ & $\mathrm{IAE}_{f}$ & $\mathrm{IAE}_{P 3}$ & $\mathrm{IAE}_{\mathrm{Q3}}$ \\
\hline Without wind or PV & 1.196 & $1.314 \times 10^{-2}$ & 0.818 & 0.098 & 0.559 & 0.776 \\
\hline Only wind & 0.928 & $1.082 \times 10^{-2}$ & 0.734 & 0.095 & 0.542 & 0.746 \\
\hline Only PV & 0.897 & $1.066 \times 10^{-2}$ & 0.695 & 0.092 & 0.524 & 0.714 \\
\hline PV with energy storage system & 0.846 & $1.034 \times 10^{-2}$ & 0.669 & 0.088 & 0.516 & 0.701 \\
\hline PV followed by wind & 0.797 & $0.997 \times 10^{-2}$ & 0.619 & 0.086 & 0.490 & 0.692 \\
\hline Combination of wind and PV & 0.731 & $0.921 \times 10^{-2}$ & 0.481 & 0.078 & 0.445 & 0.658 \\
\hline
\end{tabular}

in Figure 9. It can be found that the frequency regulation ability of the PV station equipped with the energy storage system is greatly improved, which can well suppress the frequency fluctuation of the power system subjected to small-signal disturbance. In addition, it can help the synchronous generator to recover to the stable state in a short time.

5.3. Comparative Analysis. The integral of absolute error (IAE) of each index in different fault locations is given in Table 2, in which $\operatorname{IAE}_{x}=\int_{0}^{T}\left|x-x^{*}\right| \mathrm{d} t$ and $x^{*}$ denotes the reference of variable $x$, respectively. In particular, $\mathrm{IAE}_{\delta 12}$ of the system of combination of wind and PV is merely $61.90 \%$, $74.79 \%, 78.49 \%, 82.84 \%$, and $88.27 \%$ of that without wind and PV, only wind, only PV, PV station with energy storage system, and PV followed by wind, respectively, acquired in \#3 bus voltage drop (bold colour indicates the best results in Table 2).

\section{Conclusions}

More and more large- and medium-sized renewable energy power stations have been built and connected to the power system, and they account for an increasing proportion of the power system. It affects the stability and damping characteristics of the traditional power system. In this paper, the influence of wind power and photovoltaic energy on the stability of the power system is studied, and the main conclusions are as follows:

(a) Based on the calculation of characteristic roots, it is proved that power system integrated with wind and solar energy participating in frequency regulation has better stability.

(b) Based on the New England power system, the damping characteristics of the system can be effectively improved and the system can be more stable after the wind-solar renewable energy is incorporated into the power system.

(c) Based on the New England power system test, it is verified that the photovoltaic power station can improve its stability to a certain extent after installing the energy storage system. Particularly, $\mathrm{IAE}_{f}$ acquired by PV with energy storage system is merely $88.30 \%$ and $95.40 \%$ of that without wind or PV and only PV, respectively, on the case of bus \#3 voltage drop.

\section{Data Availability}

The data that support the findings of this study are available upon request from the corresponding author. The data are not publicly available due to privacy or ethical restrictions.

\section{Conflicts of Interest}

The authors declare no conflicts of interest.

\section{Acknowledgments}

The authors gratefully acknowledge the support of the Research and Development Start-Up Foundation of Shantou University (NTF19028) and Research on Regional Power Grid Frequency Regulation with Renewable Energy Participation (YNKJXM20191240).

\section{References}

[1] H. Zhang, Z. Lu, W. Hu, Y. Wang, L. Dong, and J. Zhang, "Coordinated optimal operation of hydro-wind-solar integrated systems," Applied Energy, vol. 242, pp. 883-896, 2019.

[2] M. Sara, E. Ahmed, N. Tamou, and B. I. Badr, "NA direct power control of a DFIG based-WECS during symmetrical voltage dips," Protection and Control of Modern Power Systems, vol. 5, no. 1, pp. 36-47, 2020.

[3] D. Xie, Y. Lu, J. Sun, and C. Gu, "Small signal stability analysis for different types of PMSGs connected to the grid," Renewable Energy, vol. 106, pp. 149-164, 2017.

[4] J. Liu, W. Yao, J. Wen et al., "Impact of power grid strength and PLL parameters on stability of grid-connected DFIG wind farm," IEEE Transactions on Sustainable Energy, vol. 11, no. 1, pp. 545-557, 2020.

[5] D. Song, X. Fan, J. Yang, A. Liu, S. Chen, and Y. H. Joo, "Power extraction efficiency optimization of horizontal-axis wind turbines through optimizing control parameters of yaw control systems using an intelligent method," Applied Energy, vol. 224, pp. 267-279, 2018. 
[6] D. R. Song, S. Y. Zheng, S. Yang et al., "Annual energy production estimation for variable-speed wind turbine at high-altitude site," Journal of Modern Power Systems and Clean Energy, 2020.

[7] B. Mokhtar, B. Antonio, C. Pierluigi, C. Guido, C. Mauro, and D. F. Pasquale, "Bayesian bootstrap quantile regression for probabilistic photovoltaic power forecasting," Protection and Control of Modern Power Systems, vol. 5, no. 3, pp. 36-47, 2020.

[8] L. Ruisheng, W. K. Peter, B. L. Wang, and F. Y. Fang, "Power quality enhancement and engineering application with high permeability distributed photovoltaic access to low-voltage distribution networks in Australia," Protection and Control of Modern Power Systems, vol. 5, no. 3, pp. 1-7, 2020.

[9] X. Yan, "A review of cyber security risks of power systems: from static to dynamic false data attacks," Protection and Control of Modern Power Systems, vol. 5, no. 3, pp. 8-19, 2020.

[10] J. I. A. Qi, Y. A. N. Gangui, C. A. I. Yuru, L. I. Yonglin, and J. Zhang, "Small-signal stability analysis of photovoltaic generation connected to weak AC grid," Journal of Modern Power Systems and Clean Energy, vol. 7, no. 2, pp. 254-267, 2019.

[11] P. He, F. Wen, G. Ledwich, and Y. Xue, "Small signal stability analysis of power systems with high penetration of wind power," Journal of Modern Power Systems and Clean Energy, vol. 1, no. 3, pp. 237-244, 2013.

[12] S. G. Sadhana, S. Ashok, and S. Kumaravel, "Small signal stability analysis of grid connected renewable energy resources with the effect of uncertain wind power penetration," Energy Procedia, vol. 117, pp. 769-776, 2017.

[13] L. Xu and Y. Wang, "Dynamic modeling and control of DFIGbased wind turbines under unbalanced network conditions," IEEE Transactions on Power Systems, vol. 22, no. 1, pp. 314323, 2017.

[14] A. Bektache and B. Boukhezzar, "Nonlinear predictive control of a DFIG-based wind turbine for power capture optimization," International Journal of Electrical Power \& Energy Systems, vol. 101, pp. 92-102, 2018.

[15] M. Fei and B. Pal, "Modal analysis of grid-connected doubly fed induction generators," IEEE Transactions on Energy Conversion, vol. 22, pp. 728-736, 2007.

[16] K. H. Lam, T. M. Lai, W. C. Lo, and W. M. To, “The application of dynamic modelling techniques to the grid-connected PV (photovoltaic) systems," Energy, vol. 46, no. 1, pp. 264-274, 2012.

[17] D. S. H. Chan and J. C. H. Phang, "Analytical methods for the extraction of solar-cell single- and double-diode model parameters from I-V characteristics," IEEE Transactions on Electron Devices, vol. 34, no. 2, pp. 286-293, 1987.

[18] D.-J. Lee and L. Wang, "Small-signal stability analysis of an autonomous hybrid renewable energy power generation/energy storage system part I: time-domain simulations," IEEE Transactions on Energy Conversion, vol. 23, no. 1, pp. 311-320, 2008.

[19] Q. Wu, Y. Huang, C. Li, Y. Gu, H. Zhao, and Y. Zhan, "Small signal stability of synchronous motor-generator pair for power system with high penetration of renewable energy," IEEE Access, vol. 7, pp. 166964-166974, 2019.

[20] O. A. Ajeigbe, J. L. Munda, and Y. Hamam, "Optimal allocation of renewable energy hybrid distributed generations for small-signal stability enhancement," Energies, vol. 12, no. 24, p. $4777,2019$.

[21] S. Gurung, S. Naetiladdanon, and A. Sangswang, "Coordination of power-system stabilizers and battery energy-storage system controllers to improve probabilistic small-signal stability considering integration of renewable-energy resources," Applied Sciences, vol. 9, no. 6, p. 1109, 2019.

[22] Z. Zeng, H. Yang, and R. Zhao, "Study on small signal stability of microgrids: a review and a new approach," Renewable and Sustainable Energy Reviews, vol. 15, no. 9, pp. 4818-4828, 2011.

[23] S. Wei, Y. Zhou, Y. Zhou, S. Li, and Y. Huang, "A possible configuration with motor-generator pair for renewable energy integration View Document," CSEE Journal of Power and Energy Systems, vol. 3, no. 1, pp. 93-100, 2017.

[24] A. U. Krismanto, N. Mithulananthan, and O. Krause, "Stability of renewable energy based microgrid in autonomous operation," Sustainable Energy Grids and Networks, vol. 13, pp. 134-147, 2018.

[25] A. Krismanto, N. Mithulananthan, and K. Y. Lee, "Comprehensive modelling and small signal stability analysis of RES-based microgrid," IFAC-PapersOnLine, vol. 48, no. 30, pp. 282-287, 2015.

[26] M. Amin and M. Molinas, "Small-signal stability assessment of power electronics based power systems: a discussion of impedance- and eigenvalue-based methods," IEEE Transactions on Industry Applications, vol. 53, no. 5, pp. 5014-5030, 2017.

[27] K. Adirak, C. K. Vira, and A. Kenneth, "Small-signal stability enhancement of power systems with renewable distributed energy resources," IFAC Proceedings Volumes, vol. 44, no. 1, pp. 513-518, 2011.

[28] Y. Pan, F. Liu, L. Chen et al., "Towards the robust small-signal stability region of power systems under perturbations such as uncertain and volatile wind generation," IEEE Transactions on Power Systems, vol. 33, no. 2, pp. 1790-1799, 2017.

[29] W. Du, Q. Fu, X. Wang, and H. F. Wang, "Small-signal stability analysis of integrated VSC-based DC/AC power systems - a review," International Journal of Electrical Power \& Energy Systems, vol. 103, pp. 545-552, 2018.

[30] X. Xi, H. Geng, and G. Yang, "Enhanced model of the doubly fed induction generator-based wind farm for small-signal stability studies of weak power system," IET Renewable Power Generation, vol. 8, no. 7, pp. 765-774, 2014.

[31] T. Knüppel, J. N. Nielsen, K. H. Jensen, A. Dixon, and J. Østergaard, "Small-signal stability of wind power system with full-load converter interfaced wind turbines," IET Renewable Power Generation, vol. 6, no. 2, pp. 79-91, 2012.

[32] A. U. Krismanto and N. Mithulananthan, "Identification of modal interaction and small signal stability in autonomous microgrid operation," IET Generation Transmission \& Distribution, vol. 12, no. 1, pp. 247-257, 2017.

[33] D. C. Das, N. Sinha, and A. K. Roy, "Small signal stability analysis of dish-Stirling solar thermal based autonomous hybrid energy system," International Journal of Electrical Power \& Energy Systems, vol. 63, pp. 485-498, 2014. 